\title{
Knowledge, Attitudes and Beliefs about Dementia in an Urban Xhosa-Speaking Community in South Africa
}

\author{
V. Khonje1, C. Milligan'1, Y. Yako', M. Mabelane', K. E. Borochowitz², C. A. de Jager ${ }^{3}$ \\ ${ }^{1}$ Faculty of Health Sciences, University of Cape Town, Cape Town, South Africa \\ ${ }^{2}$ Dementia SA, State House, Cape Town, South Africa \\ ${ }^{3}$ Division of Geriatric Medicine, Department of Medicine, University of Cape Town, Cape Town, , South Africa \\ Email: Celeste.DeJager@uct.ac.za
}

Received 9 March 2015; accepted 1 June 2015; published 4 June 2015

Copyright ( 2015 by authors and Scientific Research Publishing Inc.

This work is licensed under the Creative Commons Attribution International License (CC BY). http://creativecommons.org/licenses/by/4.0/

(c) ()

\section{Abstract}

Background: Dementia, a debilitating condition, requires particular attention in Southern Africa where there is a dearth of prevalence data. Population ageing and other risk factors are driving an increasing incidence of dementia. However, limited knowledge and understanding may impact the attitudes and practices towards persons with dementia. Aim: To investigate the relationship between the knowledge of dementia, its effect on the attitudes and practices toward people with dementia in an urban community setting. To determine the perceived availability of services for those with dementia, the awareness of elder abuse and care-giver burden. Methods: A descriptive, cross-sectional study was performed in Khayelitsha. An interviewer administered questionnaire was used with assistance from isiXhosa speaking translators. A sample of 100 individuals was surveyed door-to-door from both the informal and formal housing settlements, using cluster random sampling methods. Results: There was deficient knowledge about dementia, with an average accuracy of $53.44 \%$ on the knowledge test. Only $10 \%$ reported knowing what dementia was. Participants had generally tolerant views about people with dementia. No significant relationship was found between knowledge and attitudes about dementia. There was a significant difference between people who would share their house with a family member with dementia or send them to nursing homes $(p=0.03) .64 \%$ of participants knew what elder abuse was. $19 \% \mathrm{knew}$ of an elder who had been abused; amongst the most common forms reported were being locked alone in their house and being deprived of food. Conclusions: This study showed that knowledge about dementia was limited with no relationship to attitudes of high tolerance towards people with dementia. Elder abuse was well recognized, but poorly reported. Appropriate health promotion strategies and education should be conducted and further research should be done into dementia in South Africa. 
Keywords

\section{Dementia, Carer Burden, Elder Abuse, Prevalence}

\section{Background}

Dementia, an incapacitating disease, mostly affects older persons globally. The most common types of dementia are Alzheimer's disease (AD) and vascular dementia [1]. The diagnosis of dementia involves obtaining significant medical history from the patient and the family [2]. Thus, knowledge and awareness amongst family members is crucial to detecting the symptoms and seeking medical advice.

\subsection{Knowledge about Dementia}

Studies in other countries found knowledge and understanding of dementia to be poor amongst the general population [3]-[6] as well as being limited amongst family caregivers of individuals with dementia [4]. Knowledge about dementia is generally even lower in minority ethnic groups and low to middle income countries (LAMIC) [3] [4] [6] [7]. One study reported that even where general knowledge about dementia was present, focusing on definitions and symptoms, the "biomedical knowledge" about the causes, treatment and prevention was still very low [8]. Lack of knowledge about dementia negatively impacts on health seeking behavior [4] and on the ability of caregivers to provide adequate care [8].

\subsection{Attitudes towards People with Dementia}

People with dementia are often stigmatized, discriminated against and socially excluded. This is a major public health concern. This stigma occurs in all social classes [9]. The patients often fail to tell family members and friends or seek medical care about their health condition because of the negative reactions that might ensue [10].

Lay concepts about dementia are influenced by the cultural perspectives. For example, in some African cultures dementia symptoms are perceived as a sign of possession by evil spirits, or a punishment for sins. A study amongst British people of Indian origin [7] found that people (aged 17 - 61 years old) described old age as a time of social withdrawal and isolation. According to Sahin et al. [11] and others the majority of elderly individuals consider the occurrence of dementia in old age to be a normal phenomenon [12]. There was a significant dissociation between the concept of dementia and the typical symptoms of dementia. The term dementia is apparently treated as an independent and vague concept without awareness of its clinical symptoms. A recent study found that black Caribbean people with dementia feared being viewed as "crazy" or "mad" [13]. In contrast, a US study exploring attitudes in the African American community found little or no stigma associated with dementia, which was conceptualised as a combination of worry and stress [14].

\subsection{Elder Abuse toward Individuals with Dementia}

Elder abuse is difficult to define and poorly understood because it is often a hidden offence and the nature of the abuse alters in different regions of the world [15] [16], while it can be described as "any knowing, intentional or negligent act by a caregiver or any other person that causes harm or a serious risk of harm to a vulnerable adult" [16]. Western countries classify elder abuse as either being physical, emotional, financial, sexual and neglectful. Developing countries - especially African countries_expand their definition to include allegations of witchcraft [16].

One of the identified target groups of elder abuse includes those with dementia [16]. In some African countries, there has been witchcraft-related violence (ostracism, torture and murder) especially towards elderly widowed women [16]. In addition to gradual gross memory loss, people with dementia display behavioral disturbances, hallucinations, garbled speech and wandering [17]. These types of behavior, together with the lack of community comprehension of dementia, influence the mistreatment of older people with dementia [18].

The elderly often experience abuse from family. A caregiver's perceived burden of looking after a cognitively or physically impaired older person can be seen as a stressor that can lead to abuse. A study conducted in Hong Kong showed that mistreatment was often in the form of verbal and physical abuse, ranging from shouting, 
manhandling and beating older people [19]. Extreme physical forms of violence, such as stabbing older people with knives, burning or murdering were not reported in the study. In Southern Africa such incidents are more common, but poorly reported [15] due to beliefs that the odd behavior of PWD is synonymous with witchcraft practices [20]. Another common type of elder abuse reported by the UK National Elder Abuse Study is that of a financial nature. Reported acts of abuse included denying access to sufficient health services, despite poor family care, as this would reduce the family inheritance; identity theft with the aim of falsely obtaining loans on behalf of PWD and valuables missing without explanation [21].

\subsection{Effects on Family Caregivers}

PWD require high levels of care. The majority of PWD live in the community and approximately $75 \%$ receive care provided informally by family and friends [22]. The typical profile of a dementia caregiver is a middle aged or older female, child or spouse of the individual with dementia. One of the main differences between caregiving in the developed and developing world is in the living arrangements, whereby in the developing world PWD live in larger households with extended families [23].

Family caregivers are motivated to provide care for reasons which include a sense of love or reciprocity, spiritual fulfilment, a sense of duty, guilt, social pressures or even greed. Those caregivers who are able to identify more beneficial components of their role experience less burden, better health and relationships and greater social support [24]. Caregivers in developing countries spend a median of 3 to 6 hours a day with the PWD and 3 to 9 hours assisting with activities of daily living including bathing, feeding, and toilet assistance [23].

Carers of PWD face the difficulty of balancing caregiving with other demands such as raising children, careers and relationships and this puts them at increased risk of stress, depression and a variety of health complications [25]. The costs of looking after PWD are high and involve paying for medical consultations and residential care in later stages.

\section{Aims and Objectives}

We aimed to investigate the knowledge, attitudes and practices toward people with dementia in an isi-Xhosa speaking community in a township (Khayelitsha) in the Cape Town Metropole of the Western Cape so as to develop an appropriate health promotion intervention to increase dementia awareness in the community. The objectives of the study were to design an appropriate new dementia questionnaire in order to determine: 1) the knowledge of dementia in Khayelitsha; 2) the attitudes toward PWD; and 3) awareness of abusive practices towards PWD; and to evaluate the relationship between level of knowledge and attitudes and practices, furthermore, to assess the perceived availability of services for PWD and the problems associated with caregiving for PWD.

\section{Motivation}

It is crucial that research be done to evaluate the beliefs and practices nationwide towards PWD. This study was done to promote better awareness and education about dementia through public health promotion and to make known the need for more research. This is to be established with the support of Dementia SA, a non-government organisation that started in 2006, to minimise the impact that dementia has on individuals, families and communities.

\section{Methods}

\subsection{Study Design}

This was a cross-sectional, observational and descriptive study which started in April and ended in June, 2013. The study made use of a researcher-administered questionnaire as an instrument for data collection. The questionnaire was produced in English therefore isiXhosa translators accompanied the researchers (Appendix A) [26]. The questionnaire was adapted from a series of existing questionnaires, including an AD quiz produced by Ayalon \& Areán [27] and The Alzheimer’s Disease Knowledge Scale [28]. The questionnaire consisted of closed and open-ended questions and was divided into 5 sections: participants' demographic status, knowledge and understanding of dementia (16 items), attitudes towards PWD (7 quantitative, 1 qualitative item), practices towards PWD and challenges that carers experience (6 quantitative, 8 open-ended). The purpose of the open- 
ended questions was to gain better insight into the opinions of the community members, considering the lack of research around dementia in South Africa. Responses were used to select specific ideas, allowing the data to be converted from qualitative into quantitative data. The total number of questions was 50, 13 being open-ended and 37 being closed-ended questions.

The attitudes section of the questionnaire was based on tolerance toward those with dementia. The score was out of 8 , with 8 being most tolerant and 1 being intolerant. For the perceived causes of dementia and people's attitudes towards PWD, questions were based on a questionnaire by Crabb et al., 2012 [29]. The practices and elder abuse section of the questionnaire was drafted from three studies reporting on elder abuse. The word mental illness was substituted with the word dementia.

\subsection{Population and Sampling}

The research was conducted in the township of Khayelitsha, established in 1985 and housing a population of approximately 400,000 people in 86,000 formal and informal households in 2012 (Wikipedia). Cluster sampling groups representative of the population in terms of the socio-economic and cultural circumstances of the area were selected. The sample size included 100 individuals; the minimum sample size was estimated within $7 \%$ of the true value and an anticipated population precision of $15 \%$ [CI: 95\%] on a 50\% proportion having accurate knowledge about dementia. The study included males and females aged 18 to 80 plus. People under the age of 18 and those who lacked the mental capacity to give informed consent and respond to the questions were excluded. Participants were interviewed in their homes during the day. In cases where there was more than 1 occupant in the home, a maximum of 2 people were interviewed.

The cluster sample was selected by using a map of the area using Google maps. With the help of a site- facilitator, 3 sections in the area of Khayelitsha were chosen. It is possible that the cluster group selected may be more similar with regards to beliefs than another cluster group thus increasing the risk of bias [30]. Therefore to decrease bias, clusters were increased to 200 homes per sample area (formal and informal settlements) with the sample size limited to 100 participants.

Approval for the study was obtained from the University of Cape Town, Human Research Ethics Committee (HREC). Verbal informed consent was obtained from the participants. Vulnerable groups were protected by exclusion from the study (under 18 and those unable to give informed consent). Participants were interviewed separately to ensure privacy.

\subsection{Pilot Study}

A sample of 10 people were interviewed at the Nonceba family and counselling center in Khayelitsha for the pilot study. Each interview took approximately 30 minutes, with translators. An isiXhosa equivalent questionnaire was not prepared so the translators used a copy of the English questionnaire to guide them during the interview. Questions were altered from the published versions to improve their cultural appropriateness and tested in the pilot study. The pilot study identified certain questions that needed to be removed or rephrased to improve the questionnaire's validity, as there was no pre-existing questionnaire to validate it against in this population.

\subsection{Data Analysis}

Data analysis was performed with Stata software, version 12. Descriptive statistics such as frequencies and measures of central tendency (Means and standard deviation, or proportions with 95\% CI) were produced to summarize the data including the socio-demographic characteristics. In addition, independent T-tests were performed to compare knowledge scores by sex, employment and type of accommodation. Histograms were used to demonstrate the spread of the data. Furthermore hypothesis testing was performed with Chi-squared tests to evaluate the relationship between specific categorical variables, such as beliefs and attitudes toward individuals with dementia, and elder abuse. Pearson's correlations were performed to establish associations between variables (e.g. living in the community vs in nursing homes).

\section{Results}

There was a $100 \%$ response to the questionnaire from the study sample consisting of a $100 \%$ Black African population (Table 1). The majority of the participants were female (68\%), Xhosa speaking (98\%), Christian 
Table 1. Demographic characteristics of participants $n=100$.

\begin{tabular}{|c|c|c|}
\hline Demographic factor & Category & Percentage \\
\hline \multirow[t]{4}{*}{ Age } & $18-30$ & 28 \\
\hline & $31-45$ & 28 \\
\hline & $46-60$ & 27 \\
\hline & $>60$ & 17 \\
\hline \multirow[t]{2}{*}{ Gender } & female & 68 \\
\hline & male & 32 \\
\hline \multirow[t]{4}{*}{ Home language } & isiXhosa & 98 \\
\hline & English & 1 \\
\hline & Afrikaans & 0 \\
\hline & other & 1 \\
\hline \multirow[t]{4}{*}{ Religion } & Christian & 78 \\
\hline & Traditional African & 8 \\
\hline & Muslim/Hindu & 0 \\
\hline & No religion & 14 \\
\hline \multirow[t]{4}{*}{ Highest level of education } & None & 0 \\
\hline & Primary school & 17 \\
\hline & Secondary school & 78 \\
\hline & Tertiary & 5 \\
\hline \multirow[t]{4}{*}{ Occupation } & Employed (part time and full time) & 18 \\
\hline & Self employed & 7 \\
\hline & Unemployed & 62 \\
\hline & Retired & 13 \\
\hline \multirow[t]{5}{*}{ Monthly household income } & $<\mathrm{R} 1000$ & 21 \\
\hline & R1000 - 4999 & 61 \\
\hline & R5000 - 9999 & 8 \\
\hline & $>10000$ & 1 \\
\hline & No answer & 9 \\
\hline \multirow[t]{2}{*}{ Type of house } & Formal house & 48 \\
\hline & Informal house & 52 \\
\hline \multirow[t]{4}{*}{ Number of occupants in house } & $<2$ & 4 \\
\hline & $2-4$ & 60 \\
\hline & $5-10$ & 35 \\
\hline & $>10$ & 1 \\
\hline \multirow[t]{2}{*}{ Number of occupants over 60} & 0 & 68 \\
\hline & 1 & 22 \\
\hline
\end{tabular}




\section{Continued}

\begin{tabular}{|c|c|c|}
\hline & 2 & 10 \\
\hline \multirow[t]{5}{*}{ Marital status } & Married & 35 \\
\hline & Divorced & 3 \\
\hline & Single & 36 \\
\hline & Stable relationship & 21 \\
\hline & Widowed & 5 \\
\hline \multirow[t]{2}{*}{ Family member with dementia } & Yes & 16 \\
\hline & No & 84 \\
\hline \multirow[t]{2}{*}{ Friend with dementia } & Yes & 11 \\
\hline & No & 89 \\
\hline
\end{tabular}

(78\%), unemployed (62\%) and had a total household income of approximately \$455 (ZAR1000 - R4999) (61\%) per month. The number of people interviewed within each age group was roughly equivalent. $60 \%$ of the households had 2 - 4 people living in the house, 22\% had people over the age of 60 living in the house, with $10 \%$ having more than 1 person over the age of 60 . Sixteen participants reported having a family member with dementia and 11 reported having a friend with dementia.

\subsection{Questionnaire}

When asked directly if they knew what dementia was, only $10 \%$ of participants replied positively. The average knowledge score was 8.55+/- 2.14sd [95\% CI; 8.12; 8.97] or 53.44\% accuracy (Appendix B). The question "Do you think a brain disease can be the cause of dementia?" had an $87 \%$ correct response rate. There was a minimal negative correlation between age and knowledge $(r=-0.12)$, however, this was non-significant $(p=0.25)$. There was no correlation between years of education and knowledge $(r=0.04, \mathrm{p}=0.68)$.

T-tests were used to compare knowledge scores by sex, type of accommodation, employed (yes/no) and knowing someone with dementia (yes/no). Sex and employment showed a significant relationship to knowledge, with males knowing more than females and unemployed people knowing more than employed people (Table 2).

The distribution of attitude and knowledge scores is shown in histograms (Figure 1). The mean attitude (tolerance) score was 5.78/8 +/- 1.7. The attitudes questions revealed that the proportion of those who would share their house with a family member that has dementia was high: 88\% [95\%CI: 80\%; 94\%]; those who believed that PWD were responsible for their illness was low: 7\% [95\%CI: 3\%; 14\%]. The proportion who thought PWD were dangerous and violent and to be avoided was 43\% [95\%CI: 33\%; 53\%]. The proportion who would feel ashamed having a family member with dementia and the community knowing this was 19\% [95\%CI: 12\%; $28 \%$ ]. The proportion of the sample that would be afraid of having a conversation with someone who has dementia was $11 \%$ [95\%CI: $5 \%$; $19 \%$ ], and afraid to have someone with dementia as their neighbor was $15 \%$ [95\%CI: 9\%; 24\%]. Finally the population proportion that agreed that PWD should live in the community was 67\% [95\%CI: 57\%; 76\%], while the population proportion that agreed that people with dementia should live in nursing homes was 74\% [95\%CI: 64\%; 82\%], thus a proportion (40\%) answered yes to both questions.

Since there was a large overlap between the proportions of participants who believed people with dementia should live in the community or in nursing homes, Pearson's correlations were used to identify the associations between these responses and the other variables (Table 3) to evaluate underlying perceptions. These associations were significant between the participants believing that "PWD should live in the community" versus that "PWD are dangerous or violent" $(r=0.35)$, while the association was significant between those who thought PWD should live in nursing homes versus "being ashamed to have a PWD in the family" $(r=0.27)$. There was a negative trend between those who thought PWD should live in nursing homes with "being willing to share a house with PWD”.

With regards to spiritual beliefs about dementia, four main concepts were analyzed. The population proportion that agreed that dementia was a punishment from God was 14\% [95\%CI: 7\%; 22\%]; or from the ancestors 
Table 2. T-test results between knowledge score and demographic variables.

\begin{tabular}{|c|c|c|c|c|c|}
\hline & $\mathbf{n}$ & Mean & Standard Deviation & $95 \% \mathrm{CI}$ & p-value \\
\hline \multicolumn{6}{|c|}{ Gender } \\
\hline Male & 32 & 9.22 & 2.30 & $8.39-10.05$ & \multirow{2}{*}{0.03} \\
\hline Female & 68 & 8.24 & 2.00 & $7.75-8.72$ & \\
\hline \multicolumn{6}{|c|}{ Accommodation } \\
\hline Formal & 48 & 8.58 & 2.12 & $7.95-9.22$ & \multirow{2}{*}{0.88} \\
\hline Informal & 52 & 8.51 & 2.11 & $7.93-9.11$ & \\
\hline \multicolumn{6}{|c|}{ Occupation } \\
\hline Employed & 38 & 7.95 & 2.05 & $7.27-8.62$ & \multirow{2}{*}{0.03} \\
\hline Unemployed & 62 & 8.92 & 2.12 & $8.38-9.46$ & \\
\hline \multicolumn{6}{|c|}{ Know someone with dementia } \\
\hline Yes & 27 & 8.48 & 2.12 & $7.64-9.32$ & \multirow{2}{*}{0.85} \\
\hline No & 73 & 8.58 & 2.16 & $8.07-9.08$ & \\
\hline
\end{tabular}

Table 3. The correlations between variables, specifically looking at the comparison between participants who believe people with dementia should live in the community or nursing homes.

\begin{tabular}{ccc} 
Variable & Community & Nursing homes \\
\hline Sharing a house & 0.14 & -0.19 \\
Responsible for their illness & -0.05 & 0.003 \\
Dangerous or violent & $0.35^{* *}$ & -0.04 \\
Ashamed & -0.10 & $0.27^{* *}$ \\
Afraid to have as neighbor & -0.10 & -0.03 \\
Community & & -0.09 \\
\hline
\end{tabular}

${ }^{* *}$ Correlation is significant at the 0.01 level (two-tailed).

was 18\% [95\%CI: 11\%; 27\%]; there was combined agreement of $26 \%$ that dementia was a punishment. The proportion of those who believed traditional healers can cure dementia was 15\% [95\%CI: 9\%; 24\%]. Finally the proportion of those who believed that dementia was a curse or due to witchcraft was 28\% [95\%CI: $19 \%$; 38\%]. The correlations between these beliefs were established through the use of Pearson's correlation (shown in Table 4), to identify the overlap in beliefs. There was a significant overlap between those who believed dementia was a punishment from God or from the ancestors $(r=0.54)$ and between those who thought dementia was a curse and that traditional healers can heal dementia $(r=0.30)$.

Two different methods were used to assess the relationship between knowledge and attitudes. Firstly the knowledge score was correlated against the attitude score for tolerance. The results showed no significant relationship between knowledge and attitudes $(\mathrm{p}=0.59)$.

\subsection{Qualitative Data}

Participants were asked what possible challenges or problems would occur when caring for someone with dementia. Eighty four participants gave examples of problems that may occur, while the other 16 did not know, did not respond or replied that they did not think it would be a problem. Common responses were constant watching of the person, the actual difficulty in caring for those with dementia, not knowing how to care for them and the possibility that PWD would not be cooperative when being advised or instructed. Other responses were that PWD could cause damage in the house or be a danger to themselves and others. Nevertheless many participants reported that they would be willing to care for an individual with dementia.

Knowledge and opinions on elder abuse were assessed in order to get a scope on the severity of the matter in this community. Almost two-thirds (64\%) [95\%CI: 53.79 - 73.36] of the participants understood the term “elder 


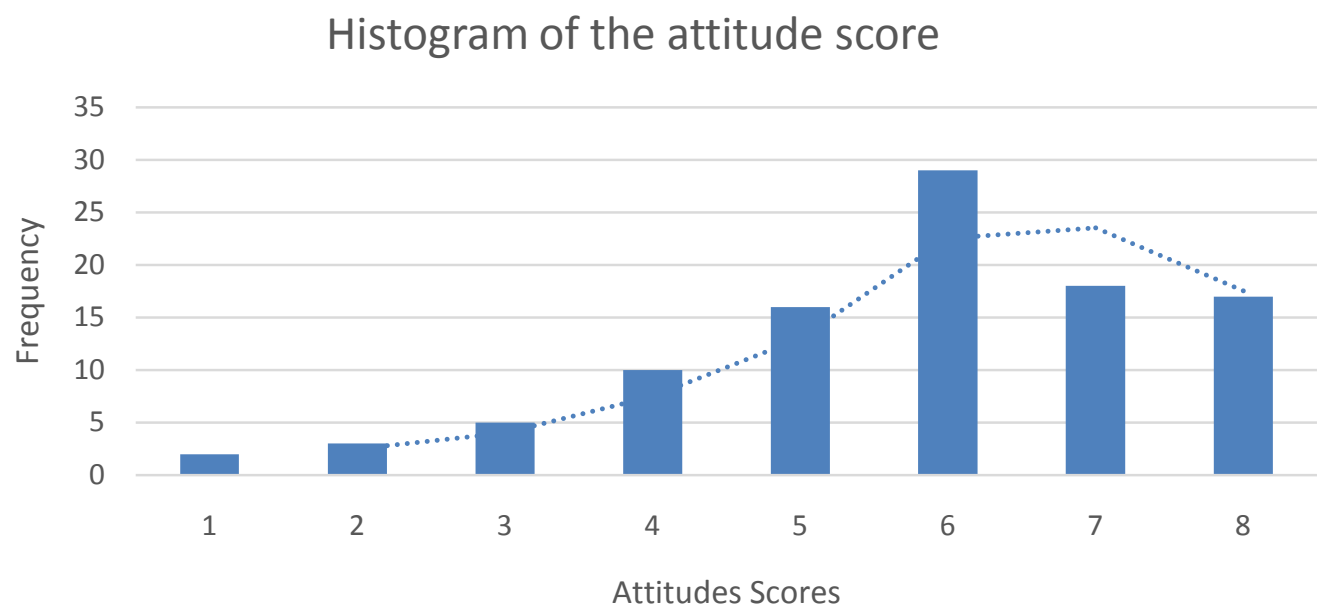

(a)

\section{Histogram chart for knowledge score}

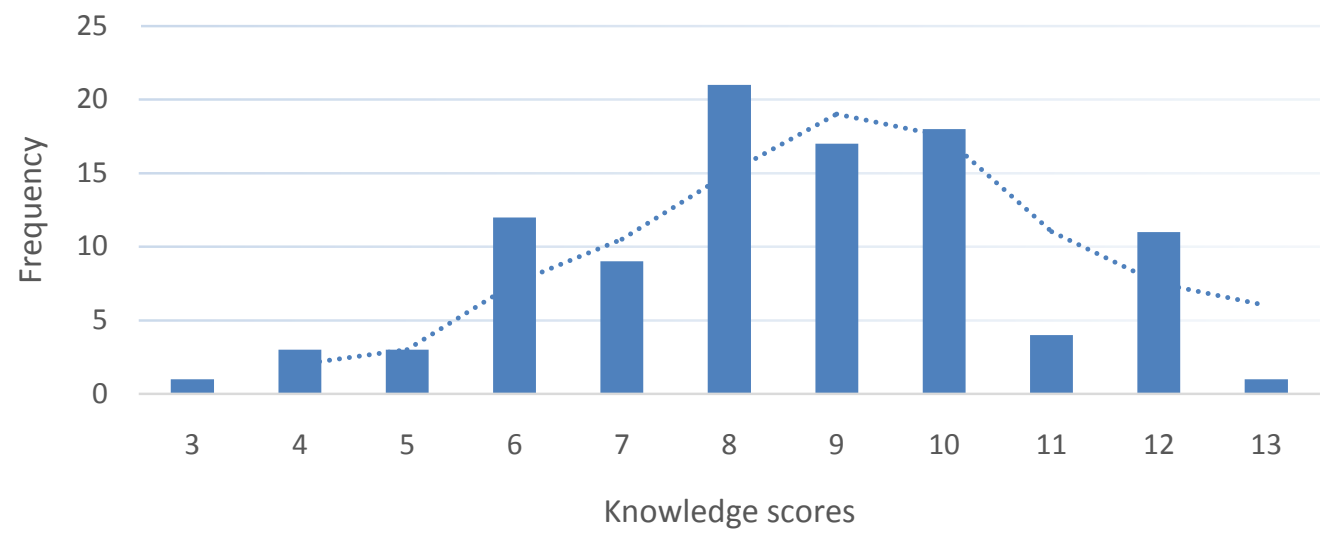

(b)

Figure 1. Histograms to depict the frequency of scores on the (a) knowledge score and (b) attitudes aspects of the dementia questionnaire, showing how many participants achieved a specific score.

abuse" and were able to describe it. However, the results revealed that a much higher proportion of participants were able to identify signs of elder abuse, namely (Table 5): verbal abuse 97\% [95\%CI: 91.48 - 99.38], neglect 93\% [95\%CI: 86.11 - 97.14], physical abuse 98\% [95\%CI: 92.96 - 99.76], rape 99\% [95\%CI: 94.55 - 99.97], sending elders to a nursing home 31\% [95\%CI: 22.13 - 41.03], stealing from elders 98\% [95\%CI: 92.96 - 99.76], locking elders in the house 97\% [95\%CI: 91.48 - 99.38]. Most of the participants were not familiar with any cases of abuse towards elders with dementia, with only 19\% [95\%CI: 11.84 - 28.07] reporting to have experienced such circumstances. Of those who reported to know an elder who had been abused, being locked in the house, stolen from and starved were the most common types of abuse (36.8\%) [95\%CI: 16.29 - 61.64], followed by physical neglect, including hygiene (26.3\%) [95\%CI: 9.15 - 51.20] and physical abuse (15.8\%) [95\%CI: 3.38 - 39.58], rape (10.5\%) [95\%CI: 1.30 - 33.14] and verbal abuse (5.3\%) [95\%CI: 0.13 - 2.60]. Cross-tabs analysis between the population proportion who knew someone who was abused because of dementia and the type of accommodation they lived in, were as follows: people residing in informal accommodation (55\%): formal accommodation (45\%), Pearson chi-squared test $=0.203$, p-value $=0.653$.

Almost all (99\%) [95\%CI: 94.55 - 99.97] participants agreed that it was important to report all cases of elder abuse and more than half (53\%) [95\%CI: 42.76 - 63.06] of the participants were aware of support services or programs that are available for elders who have reported abuse, including police services, social workers or counseling centres, such as Nonceba and Family And Marriage Society of South Africa (FAMSA), with others reporting that there were either no services (26\%) [95\%CI: 17.74 - 35.73] or they knew of none (21\%) [95\%CI: 
Table 4. The correlations between the spiritual beliefs of the participants.

\begin{tabular}{ccccc}
\hline & God & Ancestors & Curse/Witchcraft & Traditional Healers \\
\hline God & & $0.54^{* *}$ & 0.11 & -0.16 \\
Ancestors & $0.54^{* *}$ & & 0.06 & 0.02 \\
Curse/witchcraft & 0.11 & 0.06 & & $0.30^{* *}$ \\
Traditional healers & -0.16 & 0.02 & $0.30^{* *}$ & \\
\hline
\end{tabular}

${ }^{* *}$ Correlation is significant at the 0.01 level (2-tailed).

Table 5. Frequency of types of elder abuse reported.

\begin{tabular}{cccc}
\hline Type of Abuse & Frequency & Total & Percentage \\
\hline Locked & IIIII II & $7 / 19$ & $36.8 \%$ \\
Stealing & IIIII II & $7 / 19$ & $36.8 \%$ \\
Starved & IIIII II & $7 / 19$ & $36.8 \%$ \\
Neglected & IIII & $5 / 19$ & $26.3 \%$ \\
Not Bathed & IIIII & $5 / 19$ & $26.3 \%$ \\
Physical & III & $3 / 19$ & $15.8 \%$ \\
RAPE & II & $2 / 19$ & $10.5 \%$ \\
Verbal & I & $1 / 19$ & $5.3 \%$ \\
\hline
\end{tabular}

13.49 - 30.29]. In order to assess whether there were associations between the knowledge of support programs/ services available for elders who had been abused and sex, level of education and type of accommodation, crosstabs analysis with a chi-squared test was done. There were no significant results for any factor. When asked about raising awareness with regards to the abuse of elders with dementia, participants agreed that education about dementia, its causes and care for PWD was of key importance. Further suggestions were that seminars could be run in halls or clinics or that education visits be done door-to-door.

\section{Discussion}

In keeping with the international literature, the results showed that knowledge concerning dementia was very low in the isiXhosa-speaking sample surveyed. The scores on the knowledge questionnaire were higher than expected, but this may not have been an accurate reflection of people's actual knowledge levels. There was the possibility of obtaining correct answers without a full understanding of dementia. Because the majority of the participants did not know what dementia was, perceived understanding of the term "dementia” was relied upon in order for them to answer the rest of the questionnaire.

The variables in the assessment of attitude which scored the highest in agreement were being prepared to share a home with PWD, having PWD living in the community or living in nursing homes, the latter two having equal acceptability. However, living in nursing homes was not regarded as being excluded from the community by participants. This suggests that the concept may not have been well-enough defined to convey the idea that being sent to a nursing home meant being isolated from the community and being cared for by unknown caregivers rather than by family and friends, versus the idea that living in the community means not being isolated, living amongst family and friends.

Furthermore participants who agreed with PWD living in the community indicated that they were not ashamed if people knew, but at the same time they considered PWD dangerous/violent. However, the participants who agreed with PWD living in nursing homes were more negative about sharing their home with a family member with dementia and about being ashamed if people knew they had a family member with dementia (Table 3). Nevertheless according to the attitude score participants had overall tolerance toward PWD. This is contrary to the global beliefs toward those with dementia and mental illness, where the common attitude is one of neglect from the community and isolation from society [29]. These contrasting attitudes suggest that partici- 
pants were influenced by the interviewers to answer as expected rather than truthfully; or it may be assumed that the people of Khayelitsha actually have fewer stigmas toward those with dementia. Moreover they may have more traditional respect for elders and willingness to accept responsibility for the care of family members. This reflects other reports in the literature, as the general understanding is that PWD are more vulnerable than other elders thus needing help with a greater expectation of care from the family than from outside carers, especially in LAMIC [31] [32]. However, the attitudes of our study participants were largely not based on experience with PWD.

The spiritual beliefs of the participants in relation to their understanding of dementia, was evaluated. It was evident that most believed that dementia was not a punishment from God, nor from the ancestors. However, there were a substantial proportion of participants with the belief in dementia as a punishment. There were a similar proportion of participants who believed that dementia was due to a curse or witchcraft and about half of these people also believed that traditional healers could heal dementia. This finding is supported by other reports of African cultural beliefs that overlap with the ideas that dementia is a sign of possession or a punishment of sins [18].

With regards to the care-giver burden: one of the most frequent perceived challenges of caring for PWD was constant watching or caring for PWD as most did not know how to care for PWD or had other duties, such as caring for children or jobs. This challenge is supported by reports that on average caregivers can spend up to 9 hours a day caring for an individual with dementia [32] [33].

Examples of elder abuse were easily recognized on direct questioning, although only 19\% knew of an elder who had been abused due to their dementia. This could be due to the fact that much of this abuse was under-reported, here as elsewhere; however, only $27 \%$ of the participants knew someone with dementia [22]. Locking elders in the house, stealing from and starving them were the most common types of abuse reported. These results are in keeping with existing studies [23] [30]. Reports of abuse related to witchcraft allegations which occurred in developing countries, more common in African countries [23], were unreported by the participants. Yan \& Kwok described how elder abuse was commonly committed by family members, as was the case in this study [19]. All the participants who reported knowing an abused elder mentioned that abuse was by a family member, be it their children, grandchildren or siblings. Knowledge of support services/programs for abused elders was found to be quite varied, with just over half the participants reporting awareness of such services. Reasons for this variation was unfounded, with there being no significant difference between the sexes, level of education (primary versus higher education) or type of accommodation (formal versus informal).

\subsection{Limitations}

The first limitation noted in this study was interviewer bias. 98\% of the population was Xhosa-speaking, necessitating the use of isiXhosa translators. The challenge was that there was no Xhosa name/term for dementia. Providing a definition that was both medically accurate and understandable in lay terms was difficult; therefore the term dementia may not have been understood. The standardization of the questionnaire may be in questionas each translator could have interpreted the questions differently and conveyed the questions differently to the participants. These factors could have contributed to compromising the validity of the questionnaire.

Secondly, the questionnaire included some ambiguous questions; while some of these questions were eliminated after the pilot study, a few were missed and only detected when the data were being analyzed. For example, questions could have been structured as "either-or" choice questions in order to avoid overlapping responses e.g. to "PWD living at home $\mathrm{v}$ in nursing homes. Recall bias may have occurred in the section of the questionnaire on elder abuse; here the incidents of abuse relied solely on the participants” reports. Lastly there is the limitation of quantitative analysis in this type of study where a qualitative approach may have been more appropriate to exploring correct understanding of concepts about dementia.

\subsection{Recommendations}

Two categories for recommendations were identified.

\subsubsection{Methodology}

The questionnaire should be translated into isiXhosa to standardize it and eliminate interviewer bias. Ambiguous questions should be revised for more comprehensive analysis of the data. 


\subsubsection{Education}

Knowledge concerning the causes, the symptoms and diagnosis of dementia needs to be promulgated into both schools and urban and rural Xhosa communities. This could be done through community workshops in venues with mass capacity, such as halls. Secondly, community awareness about dementia could be raised via community health care workers and existing support services. It would be beneficial to the community to establish dementia-specific support services for those who have specific concerns, including carer-burden related problems. Lastly, we encourage further research into dementia prevalence, causes and risk factors as well as carer-burden and beliefs in South Africa (qualitative and quantitative), as the condition needs to be better understood in this LAMIC context to enable appropriate support and interventions to be introduced.

\section{Conclusion}

The key findings in this study show that there is no difference in the knowledge, attitudes and practices towards people with dementia in terms of demographic characteristics. In general, there is very limited knowledge and understanding of dementia in the urban Western Cape Xhosa-speaking community sampled. Some spiritual beliefs revealed the lack of knowledge about the causes of dementia. People's tolerance towards PWD was not influenced by their knowledge about dementia. Also very importantly people were able to identify indicators of abuse of elders with dementia. The majority of the participants denied knowing a person with dementia who had been abused; however, they knew of the services available in the community for abused people. Further research needs to be conducted on this topic to enable implementation of appropriate interventions, health promotion strategies and workshops.

\section{Acknowledgements}

We are grateful to Dementia SA under director KE Borochowitz, for providing resources for health promotion; to the School of Public health, Faculty of Health Sciences at UCT for support and funding of the research, for coordinating the study and assisting with approaching community leaders for permission to work in the area. We would also like to acknowledge all the participants who voluntarily took part in the study.

\section{Conflict of Interests}

Dementia SA had no role in the study design, data collection, analysis and interpretation of data.

\section{References}

[1] WHO (2012) Dementia: A Public Health Priority. World Health Organization, Geneva. http://www.who.int/mental_health/publications/dementia_report_2012/en/

[2] Ogunniyi, A., Baiyewu, O., Gureje, O., Hall, K.S., Unverzagt, F., Siu, S.H., et al. (2000) Epidemiology of Dementia in Nigeria: Results from the Indianapolis-Ibadan Study. European Journal of Neurology, 7, 485-490. http://dx.doi.org/10.1046/j.1468-1331.2000.00124.x

[3] Purandare, N., Luthra, V., Swarbrick, C. and Burns, A. (2007) Knowledge of Dementia among South Asian (Indian) Older People in Manchester, UK. International Journal of Geriatric Psychiatry, 22, 777-781. http://dx.doi.org/10.1002/gps.1740

[4] Garvey, G., Simmonds, D., Clements, V., O’Rourke, P., Sullivan, K., Gorman, D., et al. (2011) Making Sense of Dementia: Understanding amongst Indigenous Australians. International Journal of Geriatric Psychiatry, 26, 649-656. http://dx.doi.org/10.1002/gps.2578

[5] Connell, C.M., Scott Roberts, J. and McLaughlin, S.J. (2007) Public Opinion about Alzheimer Disease among Blacks, Hispanics, and Whites: Results from a National Survey. Alzheimer Disease \& Associated Disorders, 21, $232-240$. http://dx.doi.org/10.1097/WAD.0b013e3181461740

[6] Arai, Y., Arai, A. and Zarit, S.H. (2008) What Do We Know about Dementia?: A Survey on Knowledge about Dementia in the general Public of Japan. International Journal of Geriatric Psychiatry, 23, 433-438. http://dx.doi.org/10.1002/gps.1977

[7] La Fontaine, J., Ahuja, J., Bradbury, N.M., Phillips, S. and Oyebode, J.R. (2007) Understanding Dementia amongst People in Minority Ethnic and Cultural Groups. Journal of Advanced Nursing, 60, 605-614.

http://dx.doi.org/10.1111/j.1365-2648.2007.04444.x

[8] Adamson, J. (2001) Awareness and Understanding of Dementia in African/Caribbean and South Asian Families. 
Health \& Social Care in the Community, 9, 391-396. http://dx.doi.org/10.1046/j.0966-0410.2001.00321.x

[9] Putman, S. (2008) Mental Illness: Diagnostic Title or Derogatory Term? (Attitudes towards Mental Illness) Developing a Learning Resource for Use within a Clinical Call Centre. A Systematic Literature Review on Attitudes towards Mental Illness. Journal of Psychiatric and Mental Health Nursing, 15, 684-693. http://dx.doi.org/10.1111/j.1365-2850.2008.01288.x

[10] Audu, I.A., Idris, S.H., Olisah, V.O. and Sheikh, T.L. (2013) Stigmatization of People with Mental Illness among Inhabitants of a Rural Community in Northern Nigeria. International Journal of Socical Psychiatry, 59, 55-60. http://dx.doi.org/10.1177/0020764011423180

[11] Sahin, H.A., Gurvit, I.H., Emre, M., Hanagasi, H.A., Bilgic, B. and Harmanci, H. (2006) The Attitude of Elderly Lay People towards the Symptoms of Dementia. International Psychogeriatrics, 18, 251-258. http://dx.doi.org/10.1017/S1041610205002784

[12] Corner, L. and Bond, J. (2004) Being at Risk of Dementia: Fears and Anxieties of Older Adults. Journal of Aging Studies, 18, 143-155. http://dx.doi.org/10.1016/j.jaging.2004.01.007

[13] Lawrence, V., Samsi, K., Banerjee, S., Morgan, C. and Murray, J. (2011) Threat to Valued Elements of Life: The Experience of Dementia across Three Ethnic Groups. The Gerontologist, 51, 39-50. http://dx.doi.org/10.1093/geront/gnq073

[14] Dilworth-Anderson, P. and Gibson, B.E. (2002) The Cultural Influence of Values, Norms, Meanings, and Perceptions in Understanding Dementia in Ethnic Minorities. Alzheimer Disease \& Associated Disorders, 16, S56-S63. http://dx.doi.org/10.1097/00002093-200200002-00005

[15] Fitzpatrick, M.J. and Hamill, S.B. (2010) Elder Abuse: Factors Related to Perceptions of Severity and Likelihood of Reporting. Journal of Elder Abuse \& Neglect, 23, 1-16. http://dx.doi.org/10.1080/08946566.2011.534704

[16] Ferreira, M. (2005) Elder Abuse in Africa: What Policy and Legal Provisions Are There to Address the Violence? Journal of Elder Abuse \& Neglect, 16, 17-32. http://dx.doi.org/10.1300/J084v16n02_02

[17] Selwood, A., Cooper, C. and Livingston, G. (2007) What Is Elder Abuse-Who Decides? International Journal of Geriatric Psychiatry, 22, 1009-1012. http://dx.doi.org/10.1002/gps.1781

[18] Wigglesworth, A., Mosqueda, L., Mulnard, R., Liao, S., Gibbs, L. and Fitzgerald, W. (2010) Screening for Abuse and Neglect of People with Dementia. Journal of the American Geriatrics Society, 58, 493-500. http://dx.doi.org/10.1111/j.1532-5415.2010.02737.x

[19] Yan, E. and Kwok, T. (2011) Abuse of Older Chinese with Dementia by Family Caregivers: An Inquiry into the Role of Caregiver Burden. International Journal of Geriatric Psychiatry, 26, 527-535. http://dx.doi.org/10.1002/gps.2561

[20] Remember Their Names, Victims of Witch-Hunts in South Africa 2010-2012 [Internet]. South African Pagan Rights Alliance. http://www.paganrightsalliance.org/remember-their-names/

[21] Manthorpe, J., Samsi, K. and Rapaport, J. (2012) Responding to the Financial Abuse of People with Dementia: A Qualitative Study of Safeguarding Experiences in England. International Psychogeriatrics, 24, 1454-1464. http://dx.doi.org/10.1017/S1041610212000348

[22] Schulz, R. and Martire, L.M. (2004) Family Caregiving of Persons with Dementia: Prevalence, Health Effects, and Support Strategies. American Journal of Geriatric Psychiatry, 12, 240-249. http://dx.doi.org/10.1176/appi.ajgp.12.3.240

[23] Prince, M. (2004) Care Arrangements for People with Dementia in Developing Countries. International Journal of Geriatric Psychiatry, 19, 170-177. http://dx.doi.org/10.1002/gps.1046

[24] Cohen, C.A., Colantonio, A. and Vernich, L. (2002) Positive Aspects of Caregiving: Rounding Out the Care-Giver Experience. International Journal of Geriatric Psychiatry, 17, 184-188. http://dx.doi.org/10.1002/gps.561

[25] Cassie, K. and Sanders, S. (2008) Familial Caregivers of Older Adults. Handb. Psychosoc. Interv. Older Adults Evidence-Based Approaches. Haworth Press, 293-320.

[26] Joubert, G. and Ehrlich, R. (2007) Epidimiology. A Research Manual for South Africa. 2nd Edition, Oxford University Press, South Africa.

[27] Ayalon, L. and Areán, P.A. (2004) Knowledge of Alzheimer’s Disease in Four Ethnic Groups of Older Adults. International Journal of Geriatric Psychiatry, 19, 51-57. http://dx.doi.org/10.1002/gps.1037

[28] Carpenter, B.D., Balsis, S., Otilingam, P.G., Hanson, P.K. and Gatz, M. (2009) The Alzheimer's Disease Knowledge Scale: Development and Psychometric Properties. The Gerontologist, 49, $236-247$. http://dx.doi.org/10.1093/geront/gnp023

[29] Crabb, J., Stewart, R.C., Kokota, D., Masson, N., Chabunya, S. and Krishnadas, R. (2012) Attitudes towards Mental Illness in Malawi: A Cross-Sectional Survey. BMC Public Health, 12, 541. http://dx.doi.org/10.1186/1471-2458-12-541 
[30] Knopman, D.S., DeKosky, S.T., Cummings, J.L., Chui, H., Corey-Bloom, J., Relkin, N., et al. (2001) Practice Parameter: Diagnosis of Dementia (an Evidence-Based Review) Report of the Quality Standards Subcommittee of the American Academy of Neurology. Neurology, 56, 1143-1153. http://dx.doi.org/10.1212/WNL.56.9.1143

[31] Prince, M.J. (2009) The 10/66 Dementia Research Group-10 Years on. Indian Journal of Psychiatry, 51, S8-S15.

[32] Alzheimer's Disease International (2013) World Alzheimer Report 2013. Journey of Caring. An Analysis of LongTerm Care for Dementia. Chapters 1 and 3, pp. 12-17, 25-29. http://www.alz.co.uk/research/WorldAlzheimerRepor2013.pdf

[33] Vitaliano, P.P., Zhang, J. and Scanlan, J.M. (2003) Is Caregiving Hazardous to One’s Physical Health? A Meta-Analysis. Psychological Bulletin, 129, 946-972. http://dx.doi.org/10.1037/0033-2909.129.6.946 


\section{Appendix A}

The questionnaire:

\begin{tabular}{|c|c|c|c|c|c|}
\hline Name & \multicolumn{5}{|c|}{ Age } \\
\hline Gender & Male (1) & Female (2) & \multicolumn{2}{|c|}{ Other (3) } & No answer (9) \\
\hline Home Language & Xhosa (1) & English (2) & Afrikaans (3) & Other (4) & No answer (9) \\
\hline Race & Black (1) & Coloured (2) & Indian (3) & White (4) & No answer (9) \\
\hline Religion & Christian (1) & Traditional African (2) & Muslim (3) & Hindu (4) & No religion (5) No answer (9) \\
\hline $\begin{array}{l}\text { Highest Level of } \\
\text { Education }\end{array}$ & None (1) & $\begin{array}{l}\text { Primary School } \\
\text { (Specify grade) (2) }\end{array}$ & $\begin{array}{c}\text { High School } \\
\text { (Specify grade) (3) }\end{array}$ & Tertiary (4) & No answer (9) \\
\hline Occupation & $\begin{array}{l}\text { Employed-Fulltime } \\
\text { (1) }\end{array}$ & Employed-Part-time & Self-employed (2) & Unemployed (3) & No answer (9) \\
\hline $\begin{array}{c}\text { Monthly } \\
\text { Household Income }\end{array}$ & $<\mathrm{R} 1000$ & R1000 - R4999 & R5000 - R9999 & $>\mathrm{R} 10000$ & No answer (9) \\
\hline Type of House & \multicolumn{2}{|c|}{ House(1) } & \multicolumn{2}{|c|}{ Informal house (2) } & No answer (9) \\
\hline $\begin{array}{c}\text { Number of } \\
\text { occupants in house }\end{array}$ & \multicolumn{5}{|c|}{$\begin{array}{c}\text { How old are the people who live } \\
\text { with you? }\end{array}$} \\
\hline Marital Status & Married (1) & Divorced (2) & Single (3) Stable & Relationship (4) & Widowed (5) No answer (9) \\
\hline
\end{tabular}

\section{Questionnaire about the Knowledge, Attitudes and Practices towards People with Dementia}

\section{Preface}

We are fourth year medical students from the University of Cape Town. We would like to ask you to participate in a questionnaire.

The purpose of the questionnaire is to gain a better understanding about what you believe dementia to be and your attitudes and your behaviour towards those suffering from dementia.

Your answers will assist us determining the knowledge, attitudes and practices within this community and will form a springboard for further research and improve the health services in terms of health promotion: education and awareness of dementia and in the future to implement health structures to deal with the needs of the community with regards to dementia.

All the data recorded on this sheet is confidential, therefore only the persons conducting this research will have access to these papers and no other persons. Your name will not appear in any of the information when it is reported. It is in your right to refuse to take part in this research.

You can choose not to answer a question or to stop answering questions at any time.

Do you have any questions?

\section{Knowledge}

\begin{tabular}{|c|c|c|c|c|c|}
\hline & Question: & Yes & No & Don't Know & Not Answered \\
\hline 1. & Does memory loss happen to all people as they get older? & OYes & ONo & ODon't Know & Not Answered \\
\hline 2. & $\begin{array}{l}\text { Is forgetting who your family } \\
\text { members are a normal part getting old? }\end{array}$ & OYes & ONo & ODon't Know & Not Answered \\
\hline 3. & $\begin{array}{l}\text { Is forgetting the names of } \\
\text { objects a normal part of getting old? }\end{array}$ & OYes & ONo & ODon't Know & Not Answered \\
\hline 4. & $\begin{array}{l}\text { Is having trouble with speaking } \\
\text { or understanding a normal part of getting old? }\end{array}$ & OYes & ONo & ODon't Know & Not Answered \\
\hline 5. & \multicolumn{5}{|c|}{ These symptoms form part of a medical condition, what would you call this medical condition? } \\
\hline 6. & Do you know what dementia is? & OYes & ONo & ODon't Know & Not Answered \\
\hline 7. & \multicolumn{5}{|c|}{ If yes, What is dementia? } \\
\hline
\end{tabular}


Dementia is a term used to describe various different brain disorders that are caused by dying of brain cells (degeneration). This causes a loss of thinking function and affects memory, thinking, behaviour and emotion. Dementia gets worse over time.

\begin{tabular}{cllll}
\hline $\begin{array}{c}\text { Do you have a family member with dementia? } \\
\text { Do you have a friend with dementia? }\end{array}$ & O Yes & ○ No & ○ Don't Know & ○ Not Answered \\
\hline
\end{tabular}

\section{Knowledge}

\begin{tabular}{|c|c|c|c|c|c|}
\hline 8. & Do you think dementia is normal? & OYes & ONo & ODon't Know & Not Answered \\
\hline 9. & Do you think dementia is contagious? & OYes & ONo & ODon't Know & Not Answered \\
\hline 10. & Do you think poverty can cause dementia? & OYes & $\bigcirc$ No & Don’t Know & Not Answered \\
\hline 11. & Do you think a brain disease can be the cause of dementia? & OYes & ONo & ODon't Know & Not Answered \\
\hline 12. & Do you think dementia is a punishment from God? & OYes & $\bigcirc$ No & Don't Know & Not Answered \\
\hline 13. & Do you think dementia is a punishment from ancestors? & OYes & No & Don’t Know & Not Answered \\
\hline 14. & Do you think dementia can run in families? & OYes & ONo & ODon't Know & Not Answered \\
\hline 15. & $\begin{array}{l}\text { Do you think a traumatic event or shock can result in demen- } \\
\text { tia? }\end{array}$ & OYes & ONo & ODon't Know & Not Answered \\
\hline 16. & Do you think stress in daily life can cause dementia? & OYes & ONo & ODon't Know & ONot Answered \\
\hline 17. & Do you think dementia is only a disease that affects older people? & OYes & ONo & ODon't Know & Not Answered \\
\hline 18. & $\begin{array}{l}\text { Do you think women are more likely to get dementia than } \\
\text { men? }\end{array}$ & OYes & No & ODon't Know & Not Answered \\
\hline 19. & Do you think there is a cure for dementia? & OYes & ONo & ODon't Know & Not Answered \\
\hline 20. & $\begin{array}{c}\text { Do you think people with dementia have mental } \\
\text { and physical problems? }\end{array}$ & OYes & No & ODon't Know & Not Answered \\
\hline 21. & Do you think people with dementia are mad? & OYes & ONo & ODon't Know & Not Answered \\
\hline 22. & Do you think traditional healers can heal people with dementia? & OYes & No & ODon’t Know & Not Answered \\
\hline 23. & Do you believe dementia is a curse or witchcraft? & OYes & No & Don’t Know & Not Answered \\
\hline 24. & If yes to 23 , What/who influenced these beliefs about dementia? & & & & \\
\hline 25. & What other beliefs do you have about dementia? & & & & \\
\hline
\end{tabular}

Questions that were bold were used for the knowledge score out of 16 points

\section{Attitudes}

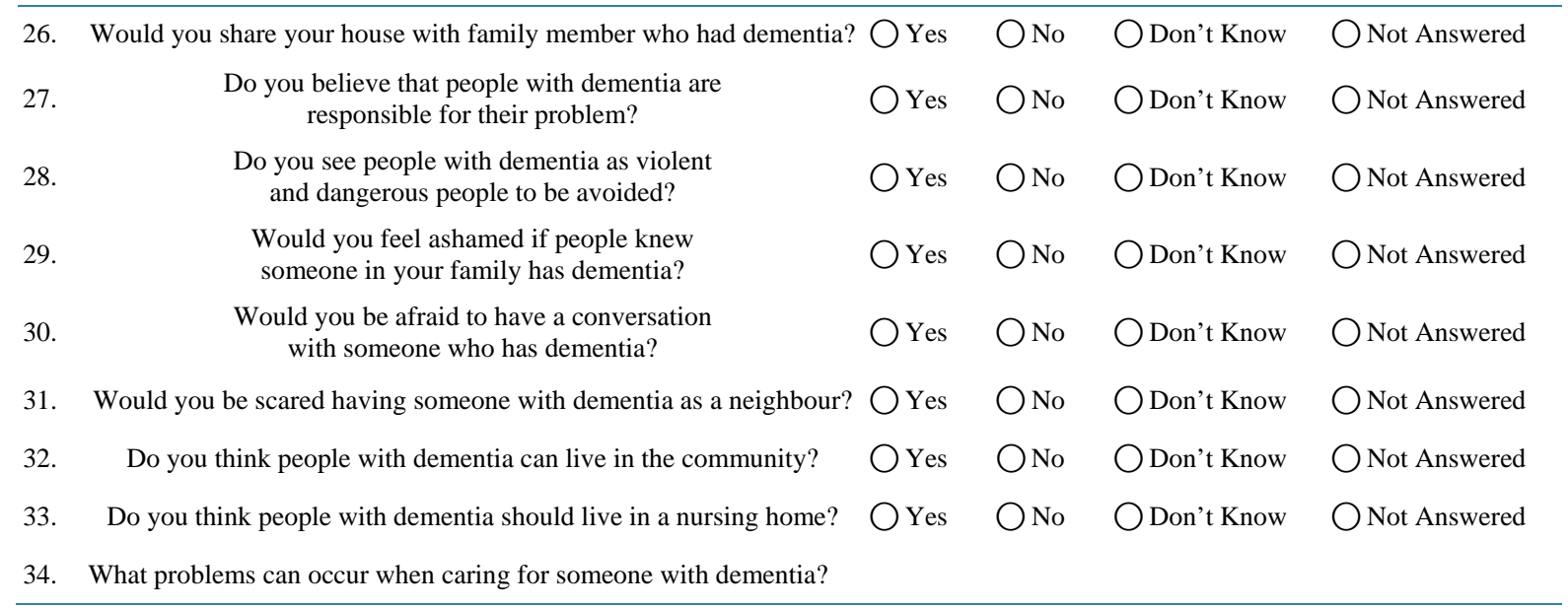




\section{Elder Abuse and Practices}

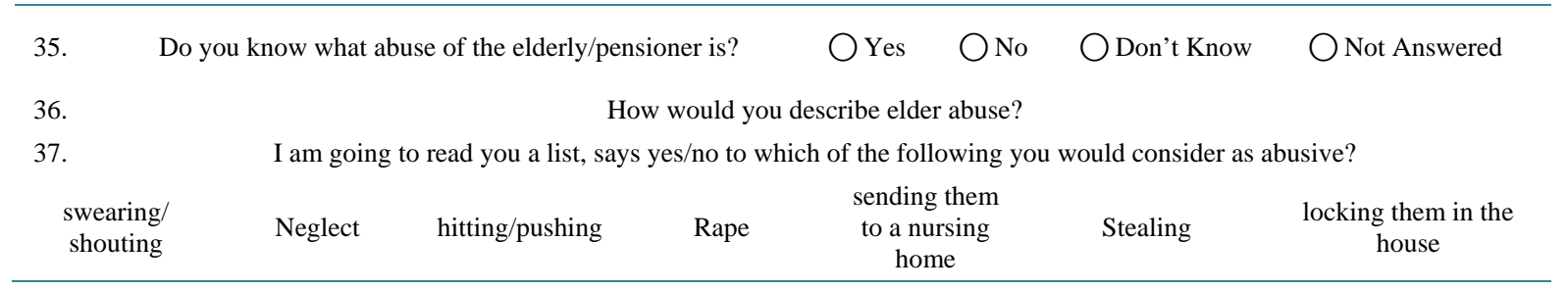

If yes to 37, ask questions 38 - 40 .

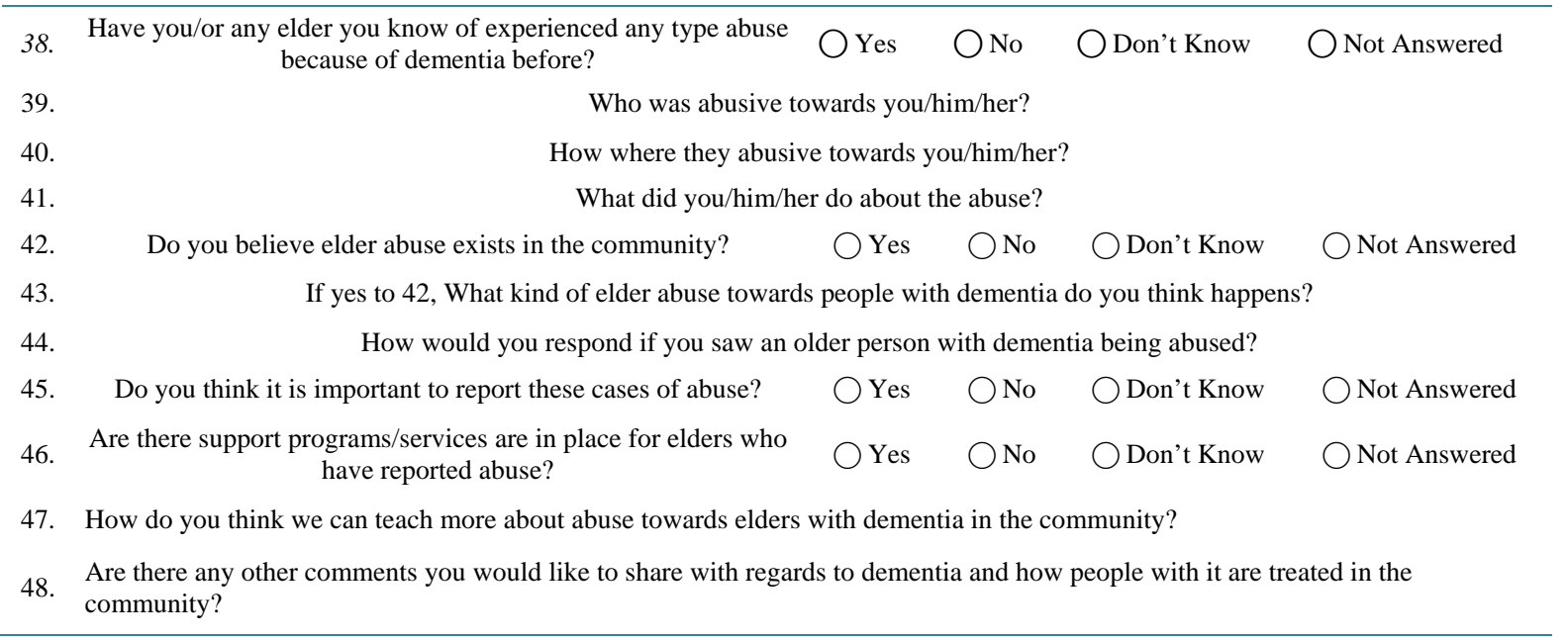

Do you have any questions?

\section{Appendix B}

Percentage correct responses for knowledge questions

\begin{tabular}{|c|c|c|}
\hline Question & $\begin{array}{l}\text { \% Correct } \\
\text { Response }\end{array}$ & $\begin{array}{l}\text { 95\% Confidence } \\
\text { Interval }\end{array}$ \\
\hline Does memory loss happen to all people as they get older? & 75 & $65.34-83.12$ \\
\hline Is forgetting who your family members are a normal part getting old? & 51 & $40.80-61.14$ \\
\hline Is forgetting the names of objects a normal part of getting old? & 45 & $35.03-55.27$ \\
\hline Is having trouble with speaking or understanding a normal part of getting old? & 36 & $26.64-46.21$ \\
\hline Do you know what dementia is? & 10 & $4.90-17.62$ \\
\hline Do you think dementia is normal? & 58 & $47.71-67.80$ \\
\hline Do you think dementia is contagious? & 69 & $58.97-77.87$ \\
\hline Do you think a brain disease can be the cause of dementia? & 87 & $78.80-92.89$ \\
\hline Do you think dementia can run in families? & 36 & $26.64-46.21$ \\
\hline Do you think a traumatic event or shock can result in dementia? & 23 & $15.17-32.48$ \\
\hline Do you think stress in daily life can cause dementia? & 6 & $2.23-12.60$ \\
\hline Do you think dementia is a disease that only affects older people? & 78 & $68.61-85.67$ \\
\hline Do you think women are more likely to get dementia than men? & 45 & $35.03-55.27$ \\
\hline Do you think there is a cure for dementia? & 42 & $32.20-52.28$ \\
\hline Do you think people with dementia have mental and physical problems? & 65 & $54.82-74.27$ \\
\hline Do you think people with dementia are mad? & 79 & $69.71-86.50$ \\
\hline TOTAL & 53.44 & $50.78-56.09$ \\
\hline
\end{tabular}

